\title{
Coulisses
}

Revue de théâtre

19| Hiver 1999

Varia

\section{Le Théâtre des romanciers}

Études réunies par Marie Miguet-Ollagnier - Annales littéraires de l'Université de Franche-Comté, 608, Série Littéraires vol. 7 - Les Belles Lettres, 1996

\section{France Marchal}

\section{OpenEdition}

\section{Journals}

Édition électronique

URL : https://journals.openedition.org/coulisses/5787

DOI : $10.4000 /$ coulisses. 5787

ISSN : 2546-9460

\section{Éditeur}

Presses universitaires de Franche-Comté

\section{Édition imprimée}

Date de publication : 1 janvier 1999

Pagination : 69-70

ISBN : 2-913322-09-3

ISSN : $1150-594 \mathrm{X}$

Référence électronique

France Marchal, «Le Théâtre des romanciers », Coulisses [En ligne], 19 | Hiver 1999, mis en ligne le 18 octobre 2019, consulté le 07 janvier 2022. URL : http://journals.openedition.org/coulisses/5787 ; DOI : https://doi.org/10.4000/coulisses.5787

Ce document a été généré automatiquement le 7 janvier 2022

Coulisses 


\title{
Le Théâtre des romanciers
}

\author{
Études réunies par Marie Miguet-ollagnier - Annales littéraires de \\ l'Université de Franche-Comté, 608, Série Littéraires vol. 7 - Les Belles \\ Lettres, 1996
}

France Marchal

1 Treize études réunies et présentées par Marie Miguet-Ollagnier commentent la tentation du théâtre chez des auteurs du XIX ${ }^{\mathrm{e}}$ ou du $\mathrm{XX}^{\mathrm{e}}$ siècle qui sont essentiellement des romanciers, de Balzac à Édouard Glissant. Qu'il s'agisse d'une unique tentative (Le Candidat de Flaubert, La Poche Parmentier de Perec, Le Fétichiste de Michel Tournier) ou d'essais rares dans une carrière, ce livre veut éclairer les motifs qui poussent un romancier à une pratique insolite, les sollicitations extérieures ou les nécessités intérieures auxquelles il répond, les réprobations et les approbations des gens de métier. Ce recueil remet en cause quelques préjugés, ceux des « critiques, notamment au XXe siècle, qui ont souvent mal accepté les incursions des romanciers dans une forme qui ne leur était pas habituelle»(p.11). La diversité des treize cas étudiés enrichit d'autant cette problématique ambitieuse.

2 Pierre Laforgue s'interroge sur les parts respectives du théâtre et de la réalité dans Le Faiseur de Balzac, pièce encore jouée de nos jours avec succès. Il avance l'hypothèse séduisante que Balzac a choisi la forme dramatique parce qu'il ne pouvait pas couler dans le moule du roman l'idée de spéculation; l'échange et la circulation des signes de la théâtralité à travers le texte s'accomplit sur le mode de l'échange et de la circulation des signes monétaires, la pièce révélant les limites historiques et idéologiques du roman balzacien. Avec Le Candidat, comédie de Flaubert représentée en 1874 sur le théâtre du Vaudeville, dont Luce Cziba éclaire la genèse, on est sans cesse confronté au roman : cette censure des mœurs politiques, cette dénonciation du suffrage universel suggère maints rapprochements avec les créations de Homais ou de Bouvard et Pécuchet. Florent Montaclair s'intéresse à une pièce de Jules Vernes montée en 1882, Voyage à travers l'impossible; elle a été préparée par l'œuvre romanesque, où l'esthétique du théâtre est partout présente, et loin d'être une adaptation, cette pièce en trois actes offre un syncrétisme de trois grands romans verniens : Voyage au centre de la terre, Vingt mille lieues sous les mers, De la Terre à la Lune. Véritable pièce d'anticipation, elle permet à 
Jules Verne de mêler musique et texte, comique et tragique, fantastique et merveilleux, le théâtre étant pour ce créateur l'authentique lieu des échanges. Le XIX ${ }^{\mathrm{e}}$ siècle est encore représenté dans ce recueil par Germinie Lacerteux, jouée à l'Odéon en 1888, tirée par Edmond de Goncourt du roman qu'il avait publié avec son frère. Philippe Baron éclaire brillamment le retour à la scène de l'auteur, sous la double influence du théâtre naturaliste et de Porel, le directeur de l'Odéon, et montre comment la création du personnage de Germinie par Réjane a été une étape importante dans la carrière de la grande actrice. Cette production, qui a suscité une bataille littéraire digne de celle d'Hernani, témoigne des difficultés du théâtre naturaliste à se constituer et de celles d'Edmond de Goncourt à passer de la forme romanesque à la forme dramatique, sa pièce restant tributaire d'une esthétique des tableaux.

3 Les études consacrées au $\mathrm{XX}^{\mathrm{e}}$ siècle commencent avec une présentation par Marie Miguet-Ollagnier de deux pièces de Céline, L'Église, comédie en cinq actes (1926) et Progrès, comédie en quatre tableaux (1927). Elles caractérisent une avant-garde prématurée, que l'auteur découvre précisément dans les critiques adressées à Céline, des personnages de carton, des pièces disparates, une écriture allégorique, un théâtre de la peste, où se révèlent bien des affinités avec Ionesco ou Tardieu. L'analyse d'une désagrégation du langage et d'une écriture dramatique qui dirigerait ce premier Céline vers le roman autobiographique complètent cette présentation très stimulante d'un dramaturge qui mériterait, selon Marie Miguet-ollagnier, de sortir du purgatoire où l'a confiné un public qui n'était pas prêt à l'accueillir. Martine Hiebel s'intéresse à un autre grand romancier, Georges Bernanos, pour tenter de circonscrire le statut des Dialogues des Carmélites, né d'une sollicitation du R. P. Brückberger qui souhaitait adapter la nouvelle de G.von Le Fort, La Dernière à l'échafaud. On passe brillamment par une analyse de l'écriture romanesque bernanosienne-le mouvement, la lumière, le dialogue - pour découvrir les exigences d'une écriture cinématographique. Thierry Miguet éclaire une double tentative de Julien Gracq : Le Roi pêcheur, représenté en 1949, création inspirée par le Parsifal de Wagner, et la traduction, pour Jean-Louis Barrault, en 1952, de la Penthésilée de Kleist, véritable réécriture. Des multiples rapprochements entre le drame wagnérien du Graal et celui d'Achille au milieu des Amazones, l'auteur tire un ensemble "opératique » dont le thème exhaustif est celui du sang, par lequel Gracq s'est totalement accompli.

Jacques Montférier montre la diversité du théâtre de François Mauriac. Asmodée, pièce jouée en 1937 à la Comédie-Française a eu du succès, mais ne doit pas faire oublier Les mal-aimés (1945), Passage du Malin (1947), pièce intéressante par son comique noir, Le feu sur la terre, créé à Lyon en 1950, sur le thème de l'inceste. On retiendra que les deux premières pièces ne sont pas indignes du modèle racinien que s'était donné le romancier, et en particulier de Phèdre. Margherita Botto voit dans celui de Julien Green un paradoxe de la communication théâtrale : pour Green le théâtre «ne serait qu'une approche détournée de l'écriture intime, et de l'écriture à la première personne dans ses œuvres narratives» (p. 171), son but serait de révéler un secret qui n'est pas, précisément, dans les éléments constitutifs de la dramaturgie. Andrée Chauvin, tout en rappelant que Perec définit la création littéraire non selon les genres mais selon les champs, montre dans La Poche Parmentier une expérience unique de l'intertextualité l'ouverture de la pièce met à contribution La Cantatrice chauve - qui sert chez les personnages une quête de l'identité et qui conduit à interpréter la pièce comme une fable de l'existence et une fable du théâtre. Nathalie Limat-Pelletier retrouve dans Théâtre/Roman d'Aragon la problématique de Julien Green déchiré entre écriture 
romanesque et aveu autobiographique. La barre typographique peut suggérer la conjonction ou la disjonction des genres, renvoie à une problématique du mentir-vrai qui est analysée avec pertinence, en particulier dans la rivalité des personnages de l'Acteur et de l'Écrivain.

5 Le recueil s'achève sur la présentation de deux pièces attachantes. Le Fétichiste de Michel Tournier, présenté par Arlette Bouloumié, fut à l'origine une création pour la télévision. En marge du théâtre, c'est le long monologue « d'un homme hors normes qui récapitule les temps forts de sa vie avec la verve d'un conteur» (p. 263), ce qui oppose cette création de Tournier au théâtre de l'absurde. Catherine Mayaux découvre dans la pièce d'Édouard Glissant, Monsieur Toussaint, créée en 1977, derrière l'unité de lieu et de temps - la pièce évoque les derniers moments de l'emprisonnement de Toussaint-Louverture au fort de Joux - l'émergence d'une véritable Histoire du monde caribéen. L'auteur finit par rejoindre son personnage dans la même conscience d'un peuple qu'il faut créer.

6 La problématique sur les genres s'enrichit donc au fil de ces pages particulièrement denses de réflexions importantes sur l'esthétique, sur l'évolution du théâtre contemporain, et même sur le statut de l'homme de lettres. Puisse ce livre d'une grande richesse susciter l'envie à telle troupe d'amateurs ou de professionnels de revenir à l'une ou l'autre des pièces commentées ici et injustement oubliées, ne serait-ce que pour tester la validité des jugements du public et de la critique.

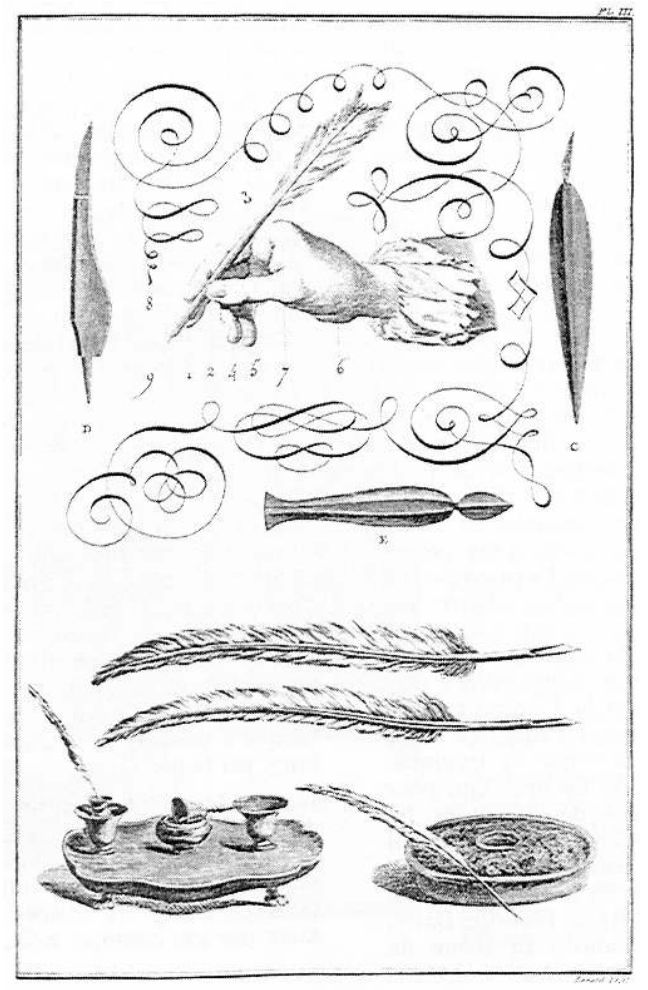

Illustration Encyclopédie de Diderot et d'Alembert 


\section{AUTEURS}

FRANCE MARCHAL

Université de Franche-Comté 